\title{
Predictors of decline in self-reported health: addressing non-ignorable dropout in longitudinal studies of aging
}

\author{
Minna Genbäck ${ }^{1,2} \cdot$ Nawi $^{2}{ }^{2,3} \cdot$ Elena Stanghellini ${ }^{4} \cdot$ Xavier de Luna $^{1}$
}

Published online: 2 December 2017

(c) The Author(s) 2017. This article is an open access publication

\begin{abstract}
Predictors of decline in health in older populations have been investigated in multiple studies before. Most longitudinal studies of aging, however, assume that dropout at follow-up is ignorable (missing at random) given a set of observed characteristics at baseline. The objective of this study was to address non-ignorable dropout in investigating predictors of declining selfreported health (SRH) in older populations (50 years or older) in Sweden, the Netherlands, and Italy. We used the SHARE panel survey, and since only 2895 out of the original 5657 participants in the survey 2004 were followed up in 2013, we studied whether the results were sensitive to the expectation that those dropping out have a higher proportion of decliners in SRH. We found that older age and a greater number of chronic diseases were positively associated with a decline in self-reported health in the three countries studies here. Maximum grip strength was associated with decline in self-reported health in Sweden and Italy, and self-reported limitations in normal activities due to health problems were associated with decline in self-reported health in Sweden. These results were not sensitive to non-ignorable dropout. On the other hand, although obesity was associated with decline in a complete case analysis, this result was not confirmed when performing a sensitivity analysis to non-ignorable dropout. The findings, thereby, contribute to the literature in understanding the robustness of longitudinal study results to non-ignorable dropout while considering three different population samples in Europe.
\end{abstract}

Keywords Longitudinal studies $\cdot$ Dropout $\cdot$ Sensitivity analysis $\cdot$ Chronic disease $\cdot$ Body mass index $\cdot$ SHARE

Responsible Editor: D.J.H. Deeg

Electronic supplementary material The online version of this article (https://doi.org/10.1007/s10433-017-0448-x) contains supplementary material, which is available to authorized users.

Minna Genbäck

minna.genback@umu.se

1 Department of Statistics, USBE, Umeå University, SE - 901 87, Umeå, Sweden

2 Centre for Demographic and Ageing Research, Umeå University, Umeå, Sweden

3 Unit of Epidemiology and Global Health, Department of Public Health and Clinical Medicine, Umeå University, Umeå, Sweden

4 Department of Economics, University of Perugia, Perugia, Italy

\section{Introduction}

As a subjective measure of overall health, self-reported health (SRH) provides an unspecific, yet comprehensive, measure of population health. Although researchers have no control over which aspects of health the individual emphasizes in their assessments of SRH (Jylhä 2009), the question itself can capture dimensions of health that more detailed health questions often miss. SRH has consistently been shown to be an important independent predictor of mortality, even after the analyses are adjusted with other more objective health indicators such as biological markers (Idler and Benyamini 1997; Kuhn et al. 2006).

Because SRH is subjective, several studies have suggested that there are differences in how different groups perceive their health, where for example women put more emphasis on disability than mortality compared to men (Deeg and Kriegsman 2003). There might also be differences between countries because cultural and linguistic factors might affect how the respondents answer the SRH question (Jylhä 2009; Jylhä et al. 1998). These differences 
in reporting SRH between population groups might lead to difficulties in comparing different studies.

A large number of cross-sectional studies have identified predictors of SRH. These predictors include socioeconomic variables such as income (Simons et al. 2013), education (Mirowsky and Ross 2008), occupation (Gueorguieva et al. 2009), social capital (Eriksson and $\mathrm{Ng} 2015$; Giordano et al. 2012), and transition into divorce or widowhood (Liu 2012); lifestyle variables such as smoking, alcohol use, and physical inactivity (Hämmig et al. 2014; Rosenkranz et al. 2013); and other health-related variables such as body mass index (Wang and Arah 2015). In summary, these earlier results indicate that better socioeconomic status and healthier lifestyle are positively associated with SRH, and either very low or very high body mass index is negatively associated with SRH.

Evidence for predictors of change in SRH over time has also been provided in longitudinal studies (Cullati et al. 2014; Svedberg et al. 2005). These predictors include age; sex (Rohlfsen and Kronenfeld 2014); socioeconomic level, including income (Giordano and Lindstrom 2010), education level (Lee et al. 2012), and labor market participation (Gueorguieva et al. 2009); health, including both physical and psychological health (Ayyagari et al. 2012; Verropoulou 2012); cognitive status; social capital (Giordano and Lindstrom 2010); and lifestyle such as alcohol consumption and physical activity (Sargent-Cox et al. 2014).

Dropout occurs in most follow-up studies, especially in studies of aging. Most missing data methods assume an ignorable dropout mechanism, i.e., that dropout is unrelated to the outcome given some measured covariates. It is well known that if this ignorability assumption is not fulfilled, the results can be biased (Little and Rubin 2002). Moreover, an ignorable dropout mechanism is unrealistic in follow-up studies where the outcome of interest is related to health, since then one expect dropout to be directly dependent on deteriorating health; see, e.g., Josefsson et al. (2016) for a practical example in a study of cognitive decline. Methods taking into account non-ignorable dropout are either based on strong identifying assumptions and/or using extra information like instrumental variables (Molenberghs et al. 2015), or, as we propose herein, estimating bounds under milder assumptions (Genbäck et al. 2015; Vansteelandt et al. 2006).

Even though there is a vast literature covering transitions in SRH, there are few covering more than one country at a time and, importantly, even fewer consider possible biases due to non-ignorable dropout. The main objectives of this study were to identify predictors of decline in SRH in older populations (50 years or older) in three European countries, while showing that evidence obtained from the data may depend on whether we ignore dropout or whether we account for the probable situation that SRH decliners are overrepresented among those dropping out at follow-up. We focused on three countries from different parts of Europe, the north (Sweden), west (Netherlands), and south (Italy), in order to corroborate results across different contexts and sampling schemes.

\section{Methods}

\section{Design, study sample, and data collection}

We analyzed data from the Survey of Health, Ageing and Retirement in Europe (SHARE). SHARE is a panel survey conducted on a random sample from the population aged 50 or older in European countries. The questionnaires were administered through face-to-face computer-assisted interviews. The first wave (baseline) started in 2004, and the last follow-up, wave 5, was conducted in 2013. The target population in each country was all residents born in 1954 or earlier, speaking the native language, and not living in prisons and similar institutions; as well as their spouses, irrespective of their age. Since the sampling process in SHARE was on a household level, all individuals in a household (almost exclusively one person or a man and a woman) were included in the sample. If both women and men were analyzed together, the samples would not have independent observations; therefore, we stratified on sex. We did not include the in-between waves since we did not want to make stronger assumptions than we currently do. Using in-between waves would imply the use of further parametric assumptions, and the sensitivity analysis would thereby become more complex. We took the two furthest observation time points to allow for larger declines. In this study, we focused on the SHARE sample in Sweden, the Netherlands, and Italy. The sampling procedure differed between countries, and thus the countries were analyzed separately. In Sweden, stratified simple random sampling from the population register was used, and in the Netherlands and Italy multi-stage sampling from regional registers (where some regions chose not to participate) was used. More details about the sampling process and target population have been published elsewhere (Börsch-Supan and Jürges 2005).

The response rate at baseline was $41 \%$ in Sweden, $54 \%$ in the Netherlands, and $44 \%$ in Italy (Börsch-Supan and Jürges 2005). Of the study sample that participated at baseline, the 9-year follow-up response rate in 2013 was 51, 48, and 57\%, respectively. We were not able to separate death from nonresponse at follow-up, since information about who was alive or dead at follow-up was only available for $16 \%$ of the individuals who dropped out.

The study sample was further limited to individuals born 1954 or earlier. As individuals living in old-age care institutions in Italy were not sampled, we excluded the individuals 
living in old-age care institutions in the other two countries to make the samples comparable. Individuals with partial missing values, or outlier values on body mass index (lower than 15 or larger than 50) were removed from the sample. Since individuals in poor health cannot decline according to our definition (see next section), we limit our study to individuals who reported "Good health" at baseline (year 2004). Figure 1 shows the exact numbers of individuals included at baseline and the numbers remaining after dropout at follow-up.

\section{Variables}

\section{Outcome variable: decline in self-reported health (SRH)}

The survey asked the respondents about their SRH using the question "Would you say your health is: excellent, very good, good, fair or poor?" We dichotomized these answers into the two categories of "Good health" (including the responses "Excellent," "Very good," or "Good") and "Poor health" ("Fair" or "Poor"). We wanted to investigate predictors of decline in SRH to the potentially harmful "Poor health" category; since only few answered poor at follow-up, we decided to include fair into the "Poor health" category. We defined the outcome to reflect the transition of SRH from baseline to the last follow-up as a binary variable taking the value of 1 if the respondents reported "Good health" at baseline and "Poor health" at the follow-up, and 0 otherwise.

\section{Covariates}

We included measures of cognitive function, health, lifestyle, and socioeconomic status at baseline in 2004 as potential predictors (SHARE Release Guide 2.6.0, Wave 1 and Wave 2.).

The measures of cognitive function consisted of mathematical performance based on a numerical test with possible scores of 1 to 5 that were dichotomized into two levels, good (scores of 4 or 5) and bad (scores of 3 or less), and the ability to state the correct date, month, year, and day of the week dichotomized into 1 if all answers were correct and 0 otherwise.

The health-related variables included the number of selfreported chronic diseases (heart attack or other heart problems; high blood pressure; high blood cholesterol; stroke; diabetes; chronic lung disease; asthma; arthritis, osteoporosis; cancer; peptic ulcer; Parkinson disease; cataracts; hip fracture; or other conditions); the number of self-reported problems with mobility (walking 100 meters; sitting for about two hours; getting up from a chair after sitting for long periods; climbing several flights of stairs without resting; climbing one flight of stairs without resting; stooping, kneeling, or crouching; reaching or extending your arms above shoulder level; pulling or pushing large objects like a living room chair; lifting or carrying weights over 5 kilos; or picking up a small coin from a table); self-reported symptoms of depression (measured using twelve questions based on the Euro-D scale developed by Prince et al. (1999) — the respondents were considered depressed if they answered positively for three or more symptoms); maximum grip strength (in kg, maximum of 4 measures using a dynamometer); self-reported limitation due to health problems in normal activities (using the global activity limitation indicator); and body mass index $\left(\mathrm{kg} / \mathrm{m}^{2}\right.$, derived from self-reported height and weight), categorized into normal weight $(<25$, reference level), overweight (25-29.9) and obesity ( $\geq 30$ ).

The lifestyle variables included smoking (categorized as current smoker, never smoked daily for at least 1 year, stopped smoking), high alcohol use (whether respondents drank more than two glasses of alcohol at least 5-6 days a week), and being inactive (if respondents answered at most 1-3 times a month on both of the questions "How often do you engage in vigorous physical activity, such as sports, heavy housework, or a job that involves physical labor?"or "How often do you engage in activities that require a low or moderate level of energy such as gardening, cleaning the car, or doing a walk?").

The socioeconomic variables consisted of education level (based on ISCED-97 code and dichotomized into "at most lower secondary education" — compulsory school—or "upper secondary education or higher") and if the household was able
Fig. 1 Flowchart of stages of inclusion in the study: the size of the study sample at baseline (box labeled "SRH good or better") and at follow-up

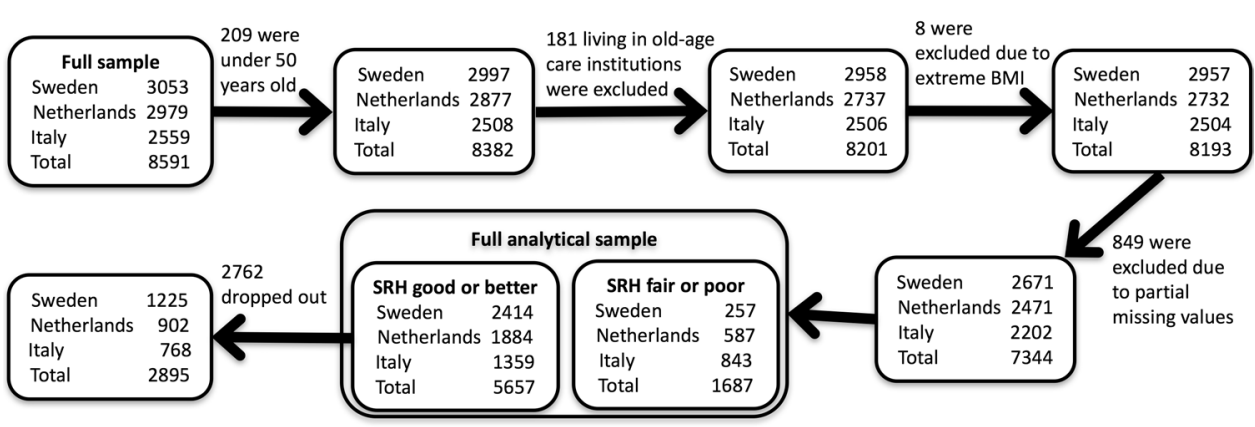


to make ends meet (dichotomized into "with great or some difficulty" or "fairly easily or easily").

We also controlled for the respondent's age and a variable that indicated whether the respondent was randomized to answer the self-perceived health question at the beginning or at the end of the questionnaire during the baseline interview.

\section{Statistical analysis}

For each country, men, and women separately, the outcome was modeled using logistic regression assuming that the dropout mechanism (indicator variable taking the value 1 if an individual participates at the follow-up and 0 if they drop out) and outcome were independent when conditioning on the observed covariates (missing at random/ignorable dropout).

We carried out a sensitivity analysis to investigate how sensitive our results were to the assumption of ignorable dropout. The sensitivity analysis that we used was adapted from the method proposed in Genbäck et al. (2015). It is described in detail together with a simplified example illustrating the ideas and concept behind such an analysis in the supplemental material. Briefly, the sensitivity analysis is based on explaining both dropout and the outcome with two regression models with the same covariates, whose two error terms are allowed to be correlated (with correlation $\rho$ ). If dropout is ignorable, then the dropout and outcome dependence is due only to the covariates included in the regression models, i.e., the error terms in the two regression models are uncorrelated. If the outcome is still associated with dropout after controlling for the covariates (i.e., $\rho$ is different from zero), dropout is called non-ignorable. This correlation $(\rho)$ is used as a sensitivity parameter, to investigate the consequence of departure from ignorable dropout. Indeed, if $\rho=0$, then we have ignorable dropout, while if $\rho=-1$, then all individuals dropping out have declined to poor SRH, and if $\rho=1$, all individuals dropping out have remained in good SRH. In this paper, only negative correlations were considered, $\rho \in[-0.8,0]$, in accordance with the realistic assumption that dropping out is in part related to poor health. We derived uncertainty intervals (the analog of confidence intervals but assuming that $\rho \in[-0.8,0]$ instead of $\rho=0$ ) that take into account uncertainty in $\rho$, and report them together with 95\% confidence intervals (assuming $\rho=0$ ) in the result tables. All the analyses were performed in R-statistical software (R Core Team 2015), and the code is freely available from the authors upon request.

\section{Results}

\section{Description of the study subjects}

The baseline characteristics of female and male respondents are summarized in Tables 1 and 2, respectively. There were slightly more female than male respondents in all countries studied.

The Swedes were slightly older (confidence intervals in Tables 1 and 2 for Swedish respondents did not overlap with those of Dutch and Italian respondents) and reported more chronic diseases, and the men reported more limitations in normal daily activities due to health problems than their counterparts in the Netherlands and Italy. A high proportion of the Swedish women had high education level and performed well in the cognitive tests. The Swedes also had a lower proportion of individuals with high alcohol use, and the Swedish men had a lower proportion of current smokers than the other countries.

The Dutch, on the other hand, reported fewer chronic diseases and had a higher grip strength compared to their counterparts in Sweden and Italy. Also, a lower proportion of the Dutch women had depressive symptoms. The Dutch men had higher education level and a higher proportion with a good score in the numerical test compared to the men in Sweden and Italy.

The Italians had the lowest proportion of respondents with high education level and good score on the numerical test, and a higher proportion of individuals with difficulty to make ends meet compared to Sweden and the Netherlands. Even though the Italians had a higher proportion of physically inactive individuals (17 and $14 \%$ among women and men, respectively, versus less than 5\% in the other two countries), they had a lower proportion of individuals who felt limited in their daily activities due to health problems. The Italians also reported more depressive symptoms and had the lowest grip strength. In the longitudinal analysis, we observed a higher proportion of Italians reporting a decline in SRH (42\% among women and 36\% among men) compared to at most $24 \%$ in the other two countries.

\section{Predictors of decline in SRH}

This study highlights age and number of chronic diseases as two predictors of decline in SRH across countries (Tables 3 and 4). Female respondents in all three countries had a higher risk of decline in SRH with increasing age.

For each additional self-reported chronic condition at baseline, the odds of decline in SRH increased, ranging from $23 \%$ (odds ratio (OR) 1.23 95\% confidence interval (CI) [1.03-1.46]) among the Swedish women to $79 \%$ (1.79 [1.39-2.30]) among the Dutch men. For the Italian women, the association between number of chronic diseases and decline in SRH was sensitive to non-ignorable dropout because the $95 \% \mathrm{CI}$ assuming ignorable dropout ([1.03-1.59]) did not contain 1, but the corresponding uncertainty interval ([0.93-1.59], shown in black in Table 3), allowing for non-ignorable dropout did. 
Table 1 Descriptive statistics for the female respondents with good or better self-rated health at baseline

\begin{tabular}{|c|c|c|c|c|c|c|}
\hline \multirow[t]{2}{*}{ Variables } & \multicolumn{2}{|c|}{ Sweden $(N=1235)$} & \multicolumn{2}{|c|}{ Netherlands $(N=985)$} & \multicolumn{2}{|c|}{ Italy $(N=682)$} \\
\hline & Value & $(95 \% \mathrm{CI})$ & Value & $(95 \% \mathrm{CI})$ & Value & $(95 \% \mathrm{CI})$ \\
\hline \multicolumn{7}{|l|}{ Baseline variables } \\
\hline Mean age in years & 63.8 & $(63.3,64.4)$ & 61.8 & $(61.2,62.3)$ & 61.9 & $(61.3,62.6)$ \\
\hline $\begin{array}{l}\% \text { who responded to the SRH question at the beginning of the } \\
\text { interview }\end{array}$ & 47.0 & $(44.2,49.9)$ & 51.8 & $(48.6,55.0)$ & 47.7 & $(43.8,51.5)$ \\
\hline \multicolumn{7}{|l|}{ Socioeconomic variables } \\
\hline$\%$ with high education level & 51.8 & $(49.0,54.7)$ & 39.6 & $(36.5,42.7)$ & 28.0 & $(24.6,31.4)$ \\
\hline$\%$ make ends meet fairly easily or easily & 80.2 & $(78.0,82.5)$ & 83.2 & $(80.9,85.6)$ & 40.5 & $(36.7,44.2)$ \\
\hline \multicolumn{7}{|l|}{ Cognitive function variables } \\
\hline$\%$ with good numeracy test & 50.8 & $(47.9,53.6)$ & 50.3 & $(47.1,53.4)$ & 25.1 & $(21.8,28.4)$ \\
\hline$\%$ with good date orientation & 93.1 & $(91.7,94.6)$ & 87.7 & $(85.6,89.8)$ & 89.6 & $(87.3,91.9)$ \\
\hline \multicolumn{7}{|l|}{ Health-related variables } \\
\hline Overweight, $25 \leq$ body mass index $<30$ & 35.8 & $(33.1,38.5)$ & 36.8 & $(33.7,39.8)$ & 37.0 & $(33.3,40.6)$ \\
\hline Obesity, body mass index $\geq 30$ & 11.8 & $(10.0,13.7)$ & 13.2 & $(11.0,15.4)$ & 14.2 & $(11.5,16.9)$ \\
\hline Mean number of chronic diseases & 1.33 & $(1.26,1.40)$ & 0.97 & $(0.90,1.05)$ & 1.15 & $(1.06,1.24)$ \\
\hline Mean number of mobility problems & 0.97 & $(0.88,1.05)$ & 0.68 & $(0.60,0.76)$ & 0.92 & $(0.81,1.04)$ \\
\hline$\%$ with depression & 35.3 & $(32.6,38.0)$ & 29.1 & $(26.2,32.0)$ & 41.6 & $(37.9,45.4)$ \\
\hline Mean of maximum grip strength in $\mathrm{kg}$ & 27.6 & $(27.3,28.0)$ & 29.8 & $(29.4,30.2)$ & 26.0 & $(25.6,26.5)$ \\
\hline$\%$ with limitation in normal activities & 37.9 & $(35.1,40.7)$ & 35.4 & $(32.4,38.5)$ & 21.4 & $(18.3,24.5)$ \\
\hline \multicolumn{7}{|l|}{ Lifestyle variables } \\
\hline$\%$ who stopped smoking & 31.7 & $(29.1,34.4)$ & 29.8 & $(26.9,32.8)$ & 16.1 & $(13.3,18.9)$ \\
\hline$\%$ who were current smokers & 18.5 & $(16.3,20.8)$ & 21.2 & $(18.6,23.8)$ & 16.4 & $(13.6,19.3)$ \\
\hline$\%$ with high alcohol usage & 1.05 & $(0.47,1.63)$ & 13.7 & $(11.5,15.9)$ & 12.9 & $(10.3,15.5)$ \\
\hline$\%$ with physical inactivity & 3.32 & $(2.30,4.34)$ & 4.26 & $(2.98,5.55)$ & 17.0 & $(14.1,19.9)$ \\
\hline \multicolumn{7}{|l|}{ Follow-up variables } \\
\hline$\%$ who were lost-to follow-up & 47.7 & & 49.6 & & 43.1 & \\
\hline$\%$ with decline in SRH among those who were followed up & 24.0 & & 23.0 & & 41.8 & \\
\hline
\end{tabular}

The complete case analysis indicates that being obese is positively associated with decline in SRH in Sweden (2.07 [1.10-3.90] among women and 2.75 [1.36-5.58] among men) and Italy (2.19 [1.10-4.37] among women and 2.38 [1.15-4.91] among men). The corresponding uncertainty intervals are [0.89-3.90], [0.95-5.58], [0.97-4.37] and [1.04-4.91]. In fact, all uncertainty intervals except for the interval for Italian males include 1 . Therefore, an association between obesity and decline in SRH is not supported by the sensitivity analysis, and we conclude that this result is sensitive to non-ignorable dropout. No significant association between being obese and decline in SRH was found for men and women in the Netherlands.

Self-reported limitations in normal activities due to health problems were associated with decline in SRH among the Swedish women (1.90 [1.20-3.02]) and men (2.66 [1.61-4.40]). High maximum grip strength protected against decline in SRH in Sweden (0.96 [0.93-0.99] among women and 0.94 [0.91-0.97] among men) and Italy (0.96 [0.92-1.00 among women and 0.96 [0.94-0.99] among men). These results were not sensitive to non-ignorable dropout.
Somewhat surprisingly, we found that being inactive seemed to be protective against decline in SRH among the Italian women (0.42 [0.22-0.83]). However, this effect was not apparent in the other country and sex combinations.

\section{Discussion}

The objective of this study was to find predictors of declining self-reported health in older populations (50 years or older) in Sweden, the Netherlands, and Italy. Since we suspected that dropout may be positively related to decline in self-reported health, we also aimed at performing a sensitivity analysis of the assumption of ignorable dropout. We found that, after taking non-ignorable dropout into account, the number of chronic diseases was a predictor in all countries (except for Italian women) and maximum grip strength was a predictor associated with decline in SRH in Sweden and Italy. The complete case analysis, i.e., ignoring dropout, indicates that obesity is a predictor of decline in SRH among Swedish and Italian men and women. However, our 
Table 2 Descriptive statistics for the male respondents with good or better self-rated health at baseline

\begin{tabular}{|c|c|c|c|c|c|c|}
\hline \multirow[t]{2}{*}{ Variables } & \multicolumn{2}{|c|}{ Sweden $(N=1179)$} & \multicolumn{2}{|c|}{ Netherlands $(N=899)$} & \multicolumn{2}{|c|}{ Italy $(N=677)$} \\
\hline & Value & $(95 \% \mathrm{CI})$ & Value & $(95 \% \mathrm{CI})$ & Value & $(95 \% \mathrm{CI})$ \\
\hline \multicolumn{7}{|l|}{ Baseline variables } \\
\hline Mean age in years & 64.7 & $(64.1,65.3)$ & 62.6 & $(62.0,63.2)$ & 63.4 & $(62.7,64.0)$ \\
\hline $\begin{array}{l}\% \text { who responded to the SRH question at the beginning of the } \\
\text { interview }\end{array}$ & 49.0 & $(46.1,51.9)$ & 48.6 & $(45.3,51.9)$ & 45.6 & $(41.8,49.5)$ \\
\hline \multicolumn{7}{|l|}{ Socioeconomic variables } \\
\hline$\%$ with high education level & 47.8 & $(44.8,50.7)$ & 57.8 & $(54.5,61.1)$ & 29.5 & $(26.0,33.0)$ \\
\hline$\%$ make ends meet fairly easily or easily & 84.1 & $(81.9,86.2)$ & 84.3 & $(81.9,86.7)$ & 39.4 & $(35.7,43.2)$ \\
\hline \multicolumn{7}{|l|}{ Cognitive function variables } \\
\hline$\%$ with good numeracy test & 63.1 & $(60.3,65.9)$ & 72.0 & $(69.0,75.0)$ & 36.0 & $(32.4,39.7)$ \\
\hline$\%$ with good date orientation & 88.3 & $(86.4,90.2)$ & 85.5 & $(83.2,87.9)$ & 86.9 & $(84.3,89.5)$ \\
\hline \multicolumn{7}{|l|}{ Health-related variables } \\
\hline Overweight, $25 \leq$ body mass index $<30$ & 48.5 & $(45.6,51.4)$ & 50.9 & $(47.6,54.3)$ & 53.9 & $(50.1,57.7)$ \\
\hline Obesity, body mass index $\geq 30$ & 12.6 & $(10.7,14.6)$ & 10.6 & $(8.5,12.6)$ & 14.8 & $(12.0,17.5)$ \\
\hline Mean number of chronic diseases & 1.32 & $(1.25,1.39)$ & 0.88 & $(0.81,0.94)$ & 1.07 & $(0.99,1.16)$ \\
\hline Mean number of mobility problems & 0.54 & $(0.48,0.61)$ & 0.30 & $(0.25,0.35)$ & 0.45 & $(0.38,0.53)$ \\
\hline$\%$ with depression & 17.0 & $(14.9,19.2)$ & 16.7 & $(14.2,19.2)$ & 25.3 & $(21.9,28.6)$ \\
\hline Mean of maximum grip strength in $\mathrm{kg}$ & 45.6 & $(45.0,46.1)$ & 47.1 & $(46.5,47.7)$ & 42.0 & $(41.3,42.8)$ \\
\hline$\%$ with limitation in normal activities & 33.6 & $(30.8,36.3)$ & 24.9 & $(22.0,27.8)$ & 14.6 & $(11.9,17.3)$ \\
\hline \multicolumn{7}{|l|}{ Lifestyle variables } \\
\hline$\%$ who stopped smoking & 45.6 & $(42.7,48.5)$ & 50.2 & $(46.8,53.5)$ & 38.0 & $(34.2,41.7)$ \\
\hline$\%$ who were current smokers & 13.7 & $(11.7,15.7)$ & 26.3 & $(23.3,29.2)$ & 23.9 & $(20.6,27.2)$ \\
\hline$\%$ with high alcohol usage & 3.05 & $(2.05,4.06)$ & 24.9 & $(22.0,27.8)$ & 43.9 & $(40.1,47.7)$ \\
\hline$\%$ with physical inactivity & 3.31 & $(2.27,4.35)$ & 4.56 & $(3.17,5.95)$ & 13.7 & $(11.1,16.4)$ \\
\hline \multicolumn{7}{|l|}{ Follow-up variables } \\
\hline$\%$ who were lost-to follow-up & 50.9 & & 54.8 & & 43.9 & \\
\hline$\%$ with decline in SRH among those who were followed up & 21.9 & & 24.4 & & 35.8 & \\
\hline
\end{tabular}

sensitivity analysis showed that three out of four associations that were significant in the complete case analysis were sensitive to non-ignorable dropout. This is in part due to there being a higher proportion of obese individuals among those that drop out than those that participate at follow-up. We concluded that there was not enough evidence in the data to consider obesity a predictor of SRH decline. This demonstrates that taking into account non-ignorable dropout, in our case implying that those with poor health may have a larger propensity to dropout, impacts the results of our longitudinal study. These results may be contrasted with Rohlfsen and Kronenfeld (2014) who found that being overweight was associated with decline in SRH for men in the USA. However, other studies did not confirm high body mass index to be a predictor of declining health (Ayyagari et al. 2012; Lee et al. 2012). The results obtained for women and men are qualitatively similar.

Our study showed that age is a predictor of decline in $\mathrm{SRH}$, even when accounting for non-ignorable dropout, which is in line with previous research (Ayyagari et al. 2012; Cullati et al. 2014; Lee et al. 2012). Multimorbidity with chronic diseases has been shown to be a predictor of decline in SRH (Hsu 2015; Lee et al. 2012), and our results confirm these findings. This is also in line with Ayyagari et al. (2012) who have identified diabetes, congestive heart failure, and angina as predictors for decline in SRH. In contrast, Rohlfsen and Kronenfeld (2014) investigated the association between several chronic diseases and change in SRH, and identified only arthritis as a predictor for health decline among women.

Some predictors were found to be significant only in some of the country/sex combinations. For instance, high maximum grip strength was found to be a predictor associated with non-decline in SRH for both men and women in Sweden and Italy, and self-reported limitations due to health problems in normal activities were associated with decline in SRH for both men and women in Sweden. The variations between countries might be due to a lack of statistical power, to the different sampling schemes, or to cultural differences in the answers provided to the outcome question "How is your health?" For instance, individuals in different countries might put emphasis on different aspects of health 
Table 3 Odds ratios and 95\% confidence intervals from the multiple logistic regressions modeling decline in SRH against all covariates for females

\begin{tabular}{|c|c|c|c|c|c|}
\hline \multirow[b]{2}{*}{ Variables } & \multicolumn{5}{|c|}{ Odds ratio ( $95 \%$ Confidence interval/CI) Sensitivity } \\
\hline & Sweden & Netherlands & Sweden & $\begin{array}{l}95 \% \mathrm{CI} \text { in } \\
\text { and } 95 \%\end{array}$ & $\begin{array}{l}\text { u color } \\
\text { UI in black }\end{array}$ \\
\hline Age (years older than 50 ) & $\begin{array}{c}1.04 \\
(1.01,1.07)\end{array}$ & $\begin{array}{c}1.06 \\
(1.03,1.10)\end{array}$ & $\begin{array}{c}1.06 \\
(1.02,1.10)\end{array}$ & 0.5 & $E$ \\
\hline $\begin{array}{l}\text { Responded to SRH question at } \\
\text { the beginning of the interview } \\
\text { (Ref: at the end) }\end{array}$ & $\begin{array}{c}0.77 \\
(0.51,1.17)\end{array}$ & $\begin{array}{c}0.97 \\
(0.61,1.55)\end{array}$ & $\begin{array}{c}0.51 \\
(0.32,0.80)\end{array}$ & & 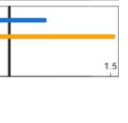 \\
\hline $\begin{array}{l}\text { Socioeconomic variables } \\
\text { High education level (Ref: low } \\
\text { education) }\end{array}$ & $\begin{array}{c}0.63 \\
(0.40,0.97)\end{array}$ & $\begin{array}{c}1.01 \\
(0.61,1.68)\end{array}$ & $\begin{array}{c}0.65 \\
(0.37,1.14)\end{array}$ & & \\
\hline $\begin{array}{l}\text { Make ends meet, easily (Ref. } \\
\text { with difficulty) }\end{array}$ & $\begin{array}{c}0.71 \\
(0.43,1.19)\end{array}$ & $\begin{array}{c}0.70 \\
(0.38,1.27)\end{array}$ & $\begin{array}{c}0.51 \\
(0.31,0.84)\end{array}$ & & - \\
\hline $\begin{array}{l}\text { Cognitive function variables } \\
\text { Good numeracy test (Ref: poor }\end{array}$ & 0.90 & 0.78 & 1.19 & & $\bar{E}$ \\
\hline $\begin{array}{l}\text { test) } \\
\text { Good date orientation (Ref: } \\
\text { poor orientation) }\end{array}$ & $\begin{array}{c}(0.59,1.38) \\
1.16 \\
(0.46,2.90)\end{array}$ & $\begin{array}{c}(0.48,1.25) \\
1.42 \\
(0.66,3.06)\end{array}$ & $\begin{array}{c}(0.68,2.08) \\
1.17 \\
(0.56,2.45)\end{array}$ & 0.5 & \\
\hline $\begin{array}{l}\text { Health-related variables } \\
\text { Overweight, } 25 \leq \text { body mass } \\
\text { index }<30 \text { (Ref: body mass }\end{array}$ & $\begin{array}{c}1.13 \\
(0.71,1.80)\end{array}$ & $\begin{array}{c}1.12 \\
(0.67,1.87)\end{array}$ & $\begin{array}{c}0.97 \\
(0.58,1.60)\end{array}$ & & \\
\hline $\begin{array}{l}\text { Obesity, body mass index } \geq 30 \\
\text { (Ref: body mass index }<25 \text { ) }\end{array}$ & $\begin{array}{c}2.07 \\
(1.10,3.90)\end{array}$ & $\begin{array}{c}1.31 \\
(0.65,2.63)\end{array}$ & $\begin{array}{c}2.19 \\
(1.10,4.37)\end{array}$ & 0.5 & \\
\hline Number of chronic diseases & $\begin{array}{c}1.23 \\
(1.03,1.46)\end{array}$ & $\begin{array}{c}1.33 \\
(1.07,1.65)\end{array}$ & $\begin{array}{c}1.28 \\
(1.03,1.59)\end{array}$ & 0.5 & \\
\hline Number of mobility problems & $\begin{array}{c}1.34 \\
(1.13,1.60)\end{array}$ & $\begin{array}{c}1.07 \\
(0.88,1.29)\end{array}$ & $\begin{array}{c}0.96 \\
(0.80,1.15)\end{array}$ & & $\overline{-}$ \\
\hline $\begin{array}{l}\text { With depression (Ref: without } \\
\text { depression) }\end{array}$ & $\begin{array}{c}0.92 \\
(0.59,1.42)\end{array}$ & $\begin{array}{c}2.19 \\
(1.37,3.51)\end{array}$ & $\begin{array}{c}1.06 \\
(0.66,1.71)\end{array}$ & & \\
\hline Maximum grip strength in $\mathrm{kg}$ & $\begin{array}{c}0.96 \\
(0.93,0.99)\end{array}$ & $\begin{array}{c}0.98 \\
(0.94,1.02)\end{array}$ & $\begin{array}{c}0.96 \\
(0.92,1.00)\end{array}$ & & \\
\hline $\begin{array}{l}\text { Limitation in normal activities } \\
\text { (Ref: no limitation) }\end{array}$ & $\begin{array}{c}1.90 \\
(1.20,3.02)\end{array}$ & $\begin{array}{c}1.56 \\
(0.94,2.58)\end{array}$ & $\begin{array}{c}1.40 \\
(0.79,2.47)\end{array}$ & 0.5 & \\
\hline $\begin{array}{l}\text { Lifestyle variables } \\
\text { Stonned smoking (Ref. never }\end{array}$ & & & & & \\
\hline $\begin{array}{l}\text { Stopped smoking (Ker: never } \\
\text { smoked) }\end{array}$ & $\begin{array}{c}0.94 \\
(0.58,1.53)\end{array}$ & $\begin{array}{c}1.04 \\
(0.59,1.83)\end{array}$ & $(0.34,1.35)$ & $\frac{5}{0.5}$ & \\
\hline $\begin{array}{l}\text { Current smokers (Ref: never } \\
\text { smoked) }\end{array}$ & $\begin{array}{c}1.27 \\
(0.69,2.34)\end{array}$ & $\begin{array}{c}2.02 \\
(1.09,3.72)\end{array}$ & $\begin{array}{c}1.05 \\
(0.56,1.98)\end{array}$ & & \\
\hline $\begin{array}{l}\text { High alcohol use (Ref: not high } \\
\text { alcohol use) }\end{array}$ & $\begin{array}{c}2.57 \\
(0.42,15.63)\end{array}$ & $\begin{array}{c}1.60 \\
(0.82,3.11)\end{array}$ & $\begin{array}{c}0.98 \\
(0.47,2.03)\end{array}$ & & \\
\hline Physical inactivity (Ref: active) & $\begin{array}{c}1.47 \\
(0.42,5.24)\end{array}$ & $\begin{array}{c}0.84 \\
(0.23,2.99)\end{array}$ & $\begin{array}{c}0.42 \\
(0.22,0.83)\end{array}$ & & \\
\hline
\end{tabular}

Figure panels show the $95 \%$ confidence interval of OR (in blue, orange, and green for Sweden, the Netherlands, and Italy, respectively) and uncertainty intervals (UI, in black). The uncertainty intervals are derived assuming that the dropout mechanism is positively correlated with decline in SRH (correlation between -0.8 and 0). (Color table online)

in their self-assessment, or there might be linguistic/translation issues and the SRH question and answer alternatives might not be interpreted in comparable ways (Jylhä 2009; Jürges 2007).

We had fairly low response rates at baseline ( $41 \%$ in Sweden, $54 \%$ in the Netherlands, and $44 \%$ in Italy). Thus, the results obtained in this study based on the respondents at baseline might not be generalizable to those that did not respond. If the two groups differ, we have no means to know how this would change the results. For $84 \%$ of the dropout individuals, we do not have information on whether the individuals were alive or not at follow-up. This information could have been used to make a distinction between dropout due to death or other reasons (Josefsson et al. 2016). However, we do not expect that a sensitivity analysis where death and other dropout causes are distinguished would yield 
Table 4 Odds ratios and 95\% confidence intervals from the multiple logistic regressions modeling decline in SRH against all covariates for males

\begin{tabular}{|c|c|c|c|c|c|}
\hline \multirow[b]{2}{*}{ Variables } & \multicolumn{5}{|c|}{ Odds ratio (95\% Confidence interval/CI) Sensitivity } \\
\hline & Sweden & Netherlands & Sweden & $\begin{array}{l}95 \% \mathrm{CI} \text { in } \\
\text { and } 95 \% \mathrm{I}\end{array}$ & $\begin{array}{l}\text { color } \\
\text { UI in black }\end{array}$ \\
\hline Age (years older than 50 ) & $\begin{array}{l}1.02 \\
(0.99,1.05)\end{array}$ & $\begin{array}{l}1.01 \\
(0.98,1.05)\end{array}$ & $\begin{array}{l}1.03 \\
(0.99,1.07)\end{array}$ & 0.5 & E \\
\hline $\begin{array}{l}\text { Responded to SRH question at } \\
\text { the beginning of the interview } \\
\text { (Ref: at the end) }\end{array}$ & $\begin{array}{l}0.86 \\
(0.55,1.35)\end{array}$ & $\begin{array}{l}0.67 \\
(0.41,1.10)\end{array}$ & $\begin{array}{l}1.40 \\
(0.89,2.23)\end{array}$ & o.s & $E$ \\
\hline $\begin{array}{l}\text { Socioeconomic variables } \\
\text { High education level (Ref: low } \\
\text { education) }\end{array}$ & $\begin{array}{l}0.74 \\
(0.46,1.19)\end{array}$ & $\begin{array}{l}0.81 \\
(0.47,1.39)\end{array}$ & $\begin{array}{l}0.85 \\
(0.49,1.46)\end{array}$ & & - \\
\hline $\begin{array}{l}\text { Make ends meet, easily (Ref. } \\
\text { with difficulty) }\end{array}$ & $\begin{array}{l}0.86 \\
(0.46,1.59)\end{array}$ & $\begin{array}{l}1.16 \\
(0.55,2.45)\end{array}$ & $\begin{array}{l}0.75 \\
(0.46,1.23)\end{array}$ & & \\
\hline $\begin{array}{l}\text { Cognitive function variables } \\
\text { Good numeracy test (Ref: poor } \\
\text { test) }\end{array}$ & 0.94 & 0.49 & $\begin{array}{l}1.13 \\
(068,188)\end{array}$ & & \\
\hline $\begin{array}{l}\text { Good date orientation (Ref: } \\
\text { poor orientation) }\end{array}$ & $(0.33,1.29)$ & $\begin{array}{l}0.64 \\
(0.33,1.24)\end{array}$ & $\begin{array}{l}0.78 \\
(0.41,1.50)\end{array}$ & & \\
\hline $\begin{array}{l}\text { Health-related variables } \\
\text { Overweight, } 25 \leq \text { body mass }\end{array}$ & 1.85 & 0.80 & & & \\
\hline index $<30$ (Ref: bc & $(1.09,3.15)$ & $(0.46,1.39)$ & $(0.81,2.35)$ & .0 .5 & \\
\hline $\begin{array}{l}\text { Obesity, body mass index } \geq 30 \\
\text { (Ref: Body mass index }<25 \text { ) }\end{array}$ & $\begin{array}{l}2.75 \\
(1.36,5.58)\end{array}$ & $\begin{array}{l}1.07 \\
(0.45,2.56)\end{array}$ & $\begin{array}{l}2.38 \\
(1.15,4.91)\end{array}$ & 0.5 & \\
\hline Number of chronic diseases & $\begin{array}{l}1.49 \\
(1.23,1.81)\end{array}$ & $\begin{array}{l}1.79 \\
(1.39,2.30)\end{array}$ & $\begin{array}{l}1.40 \\
(1.12,1.76)\end{array}$ & o.s. & \\
\hline Number of mobility problems & $\begin{array}{l}1.12 \\
(0.87,1.44)\end{array}$ & $\begin{array}{l}1.40 \\
(0.96,2.04)\end{array}$ & $\begin{array}{l}1.07 \\
(0.84,1.37)\end{array}$ & 0.5 & \\
\hline $\begin{array}{l}\text { With depression (Ref: without } \\
\text { depression) }\end{array}$ & $\begin{array}{l}0.62 \\
(0.32,1.21)\end{array}$ & $\begin{array}{l}1.16 \\
(0.61,2.22)\end{array}$ & $\begin{array}{l}0.66 \\
(0.39,1.12)\end{array}$ & & \\
\hline Maximum grip strength in $\mathrm{kg}$ & $\begin{array}{l}0.94 \\
(0.91,0.97)\end{array}$ & $\begin{array}{l}1.01 \\
(0.98,1.04)\end{array}$ & $\begin{array}{l}0.96 \\
(0.94,0.99)\end{array}$ & & \\
\hline $\begin{array}{l}\text { Limitation in normal activities } \\
\text { (Ref: no limitation) }\end{array}$ & $\begin{array}{l}2.66 \\
(1.61,4.40)\end{array}$ & $\begin{array}{l}0.96 \\
(0.52,1.78)\end{array}$ & $\begin{array}{l}1.15 \\
(0.60,2.19)\end{array}$ & & \\
\hline Lifestyle variables & & & & & \\
\hline $\begin{array}{l}\text { Stopped smoking (Ref: never } \\
\text { smoked) }\end{array}$ & $\begin{array}{l}1.01 \\
(0.62,1.64)\end{array}$ & $\begin{array}{l}0.69 \\
(0.37,1.29)\end{array}$ & $\begin{array}{l}1.02 \\
(0.60,1.75)\end{array}$ & 0.5 & \\
\hline $\begin{array}{l}\text { Current smokers (Ref: never } \\
\text { smoked) }\end{array}$ & $\begin{array}{l}1.53 \\
(0.73,3.22)\end{array}$ & $\begin{array}{l}1.25 \\
(0.61,2.57)\end{array}$ & $\begin{array}{l}1.64 \\
(0.87,3.09)\end{array}$ & & \\
\hline $\begin{array}{l}\text { High alcohol use (Ref: not high } \\
\text { alcohol use) }\end{array}$ & $\begin{array}{l}1.28 \\
(0.26,6.34)\end{array}$ & $\begin{array}{l}1.09 \\
(0.62,1.94)\end{array}$ & $\begin{array}{l}0.85 \\
(0.54,1.35)\end{array}$ & & \\
\hline Physical inactivity (Ref: active) & $\begin{array}{l}1.32 \\
(0.35,4.91)\end{array}$ & $\begin{array}{l}1.78 \\
(0.50,6.36)\end{array}$ & $\begin{array}{l}0.46 \\
(0.21,1.02)\end{array}$ & & \\
\hline
\end{tabular}

Figure panels show uncertainty intervals (in black) and a confidence interval (in blue, orange, and green for Sweden, the Netherlands, and Italy, respectively). The uncertainty intervals are derived assuming that the dropout mechanism is positively correlated with decline in SRH (correlation between -0.8 and 0 ). (Color table online)

different conclusions. For instance, a sensitivity analysis removing the 439 individuals known to be deceased yielded similar results (results not shown).

Even though there is a vast literature covering transitions in SRH, there are only few covering more than one country at a time, allowing to corroborate results in different population and sampling schemes. Moreover, most published longitudinal studies of aging assume that dropout at follow-up is ignorable (independent of the outcome) given a set of observed characteristics at baseline. However, this assumption is not realistic when a health outcome is of interest and dropout is expected to be related to health conditions. Our study is, up to our knowledge, the first one on predictors of changes in SRH that considers non-ignorable dropout. The study demonstrates that conclusions can indeed change when dropout mechanisms and SRH decline are allowed to 
be dependent on each other. The methodology presented to take into account non-ignorable dropout can be applied to any study with binary outcome observed at two time points and where non-ignorable dropout is expected.

Acknowledgments We are grateful to Marie Eriksson for helpful comments. This work was part of the project "Paths to Healthy and Active Ageing" supported by the Swedish Research Council for Health, Working Life and Welfare [Grant nr: 2013-2506]. This paper uses data from SHARE Waves 1 and 5 (DOIs: https://doi.org/10.6103/ SHARE.w1.260, https://doi.org/10.6103/SHARE.w5.100), see (Börsch-Supan et al. 2013) for methodological details. The SHARE data collection has been primarily funded by the European Commission through FP5 (QLK6-CT-2001-00360), FP6 (SHARE-I3: RIICT-2006-062193, COMPARE: CIT5-CT-2005-028857, SHARELIFE: CIT4-CT-2006-028812) and FP7 (SHARE-PREP: N²11909, SHARE-LEAP: N²27822, SHARE M4: N²61982). Additional funding came from the German Ministry of Education and Research, the US National Institute on Aging (U01_AG09740-13S2, P01_AG005842, P01_AG08291, P30_AG12815, R21_AG025169, Y1-AG-4553-01, IAG_BSR06-11, OGHA_04-064) and from various national funding sources (see www.share-project.org).

\section{Compliance with ethical standards}

Conflict of interest The authors declare that they have no conflict of interest.

Informed consent It was obtained from all individual participants included in the study.

Open Access This article is distributed under the terms of the Creative Commons Attribution 4.0 International License (http://creativecommons.org/licenses/by/4.0/), which permits unrestricted use, distribution, and reproduction in any medium, provided you give appropriate credit to the original author(s) and the source, provide a link to the Creative Commons license, and indicate if changes were made.

\section{References}

Ayyagari P et al (2012) Self-rated health trajectories in the African American health cohort. PLoS ONE 7:e53278

Börsch-Supan A, Jürges H (2005) The survey of health, aging, and retirement in Europe. Methodology, Mannheim research institute for the economics of aging (MEA)

Börsch-Supan A et al (2013) Data resource profile: the survey of health, ageing and retirement in Europe (SHARE). Int J Epidemiol 42:992-1001. https://doi.org/10.1093/ije/dyt088

Core Team R (2015) R: a language and environment for statistical computing. R Foundation for Statistical Computing, Vienna

Cullati S, Rousseaux E, Gabadinho A, Courvoisier DS, Burton-Jeangros C (2014) Factors of change and cumulative factors in selfrated health trajectories: a systematic review. Adv Life Course Res 19:14-27

Deeg DJ, Kriegsman DM (2003) Concepts of self-rated health: specifying the gender difference in mortality risk. Gerontol 43:376-386

Eriksson M, Ng N (2015) Changes in access to structural social capital and its influence on self-rated health over time for middle-aged men and women: a longitudinal study from northern Sweden. Soc Sci Med 130:250-258
Genbäck M, Stanghellini E, de Luna X (2015) Uncertainty intervals for regression parameters with non-ignorable missingness in the outcome. Stat Pap 56:829-847

Giordano GN, Lindstrom M (2010) The impact of changes in different aspects of social capital and material conditions on selfrated health over time: a longitudinal cohort study. Soc Sci Med 70:700-710

Giordano GN, Björk J, Lindström M (2012) Social capital and selfrated health-a study of temporal (causal) relationships. Soc Sci Med 75:340-348

Gueorguieva R, Sindelar JL, Falba TA, Fletcher JM, Keenan P, Wu R, Gallo WT (2009) The impact of occupation on self-rated health: cross-sectional and longitudinal evidence from the health and retirement survey. J Gerontol Ser B: Psychol Sci Soc Sci 64B: $118-124$

Hämmig O, Gutzwiller F, Kawachi I (2014) The contribution of lifestyle and work factors to social inequalities in self-rated health among the employed population in Switzerland. Soc Sci Med 121:74-84

Hsu H-C (2015) Trajectories of multimorbidity and impacts on successful aging. Exp Gerontol 66:32-38

Idler EL, Benyamini Y (1997) Self-rated health and mortality: a review of twenty-seven community studies. J Health Soc Behav 38:21-37

Josefsson M, de Luna X, Daniels MJ, Nyberg L (2016) Causal inference with longitudinal outcomes and non-ignorable dropout: estimating the effect of living alone on cognitive decline. J Roy Stat Soc: Ser C (Appl Stat) 65:131-144

Jürges H (2007) True health vs response styles: exploring cross-country differences in self-reported health. Health Econ 16:163-178

Jylhä M (2009) What is self-rated health and why does it predict mortality? Towards a unified conceptual model. Soc Sci Med 69:307-316

Jylhä M, Guralnik JM, Ferrucci L, Jokela J, Heikkinen E (1998) Is selfrated health comparable across cultures and genders? J Gerontol Ser B: Psychol Sci Soc Sci 53:S144-S152

Kuhn R, Rahman O, Menken J (2006) Survey measures of health: how well do self-reported and observed indicators measure health and predict mortality. In: Menken BCAJ (ed) Aging in sub-Saharan Africa: recommendations for furthering research. The National Academies Press, Washington, D.C., pp 314-342

Lee H-L, Huang H-C, Lee M-D, Chen JH, Lin K-C (2012) Factors affecting trajectory patterns of self-rated health (SRH) in an older population-A community-based longitudinal study. Arch Gerontol Geriatr 54:e334-e341

Little RJA, Rubin DB (2002) Statistical analysis with missing data, 2nd edn. Wiley, New Jersey

Liu H (2012) Marital dissolution and self-rated health: age trajectories and birth cohort variations. Soc Sci Med 74:1107-1116

Mirowsky J, Ross CE (2008) Education and self-rated health cumulative advantage and its rising importance. Res Aging 30:93-122

Molenberghs G, Fitzmaurice G, Kenward MG, Tsiatis A, Verbeke G (2015) Handbook of missing data methodology. CRC Press, Boca Raton

Prince MJ et al (1999) Development of the EURO-D scale-a European, Union initiative to compare symptoms of depression in 14 European centres. Br J Psychiatry 174:330-338

Rohlfsen LS, Kronenfeld JJ (2014) Gender differences in trajectories of self-rated health in middle and old age an examination of differential exposure and differential vulnerability. J Aging Health 26:637-662

Rosenkranz RR, Duncan MJ, Rosenkranz SK, Kolt GS (2013) Active lifestyles related to excellent self-rated health and quality of life: cross sectional findings from 194,545 participants in The 45 and Up Study. BMC Public Health 13:1071 
Sargent-Cox K, Cherbuin N, Morris L, Butterworth P, Anstey KJ (2014) The effect of health behavior change on self-rated health across the adult life course: a longitudinal cohort study. Prev Med 58:75-80

SHARE Release Guide 2.6.0, Wave 1 and Wave 2

Simons AMW, Groffen DAI, Bosma H (2013) Income-related health inequalities: does perceived discrimination matter? Int J Pub Health 58:513-520

Svedberg P, Gatz M, Lichtenstein P, Sandin S, Pedersen NL (2005) Self-rated health in a longitudinal perspective: a 9-year follow-up twin study. J Gerontol Ser B: Psychol Sci Soc Sci 60:S331-S340
Vansteelandt S, Goetghebeur E, Kenward MG, Molenberghs G (2006) Ignorance and uncertainty regions as inferential tools in a sensitivity analysis. Statistica Sinica 16:953-979

Verropoulou G (2012) Determinants of change in self-rated health among older adults in Europe: a longitudinal perspective based on SHARE data. Eur J Ageing 9:305-318

Wang A, Arah OA (2015) Body mass index and poor self-rated health in 49 low-income and middle-income countries, by sex, 20022004. Prev Chronic Dis 12:E133 